\title{
Meteo-climatic characterization of Naples and its heating-cooling degree day areal distribution
}

\author{
Nicola Scafetta $^{1 *}$, Alberto Fortelli $^{2}$, Adriano Mazzarella $^{1}$ \\ ${ }^{1}$ Meteorological Observatory, Department of Earth Sciences, Environment and Georesources, \\ University of Naples Federico II, Largo S. Marcellino, Naples 10 - 80138, Italy \\ ${ }^{2}$ Centro Interdipartimentale di Ricerca "Ambiente" (CIRAM) - University of Naples Federico II, \\ Via Mezzocannone, Naples 16 - 80134, Italy \\ Email: nicola.scafetta@unina.it
}

\begin{abstract}
We characterize the meteo-climate data of the urban area of Naples to determine the areal and seasonal distribution of energy demand needed to heat or cool its buildings. Naples is a one million people city facing the Tyrrhenian Sea in Central Italy with a complex morphology made of hills and valleys, spanning in altitude from 0 to $400 \mathrm{~m}$ asl. We use heating degree days (HDD) relative to a $20^{\circ} \mathrm{C}$ base and cooling degree days (CDD) relative to the humidex index with a 25 base. HDD and CDD are derived from measurements of outside air temperature and relative humidity taken from eight weather stations distributed in the urban area. The total HDD+CDD energy demand is on average 2080 with a minimum in the park of S. Elmo (1884) and a maximum in Camaldoli (2319), that are poorly populated areas. On the contrary, via Foria, the Naples' downtown and its most populated area, registers the highest energy demand (2255) because it is characterized by a weakly continental climate, while the other locations enjoy a more maritime climate. In particular, Denza on Posillipo promontory, famous for its pleasant climate, registers the lowest energy demand (1977).
\end{abstract}

Keywords: Urban Heat Island, Heating and Cooling Degree Days, City Energy Consumption, Zonation.

\section{INTRODUCTION}

Meteorological data provide an effective tool to govern the energy demand and supply to heat or cool buildings. They allow to verify whether the energy consumption depends on a real need rather than on a poorly optimized plant or on inefficient demand and supply management. In fact, counters or thermo valves report correctly the consumption but cannot indicate whether such consumption is excessive in respect to the real requirements and this to detriment of wealth, environment and health.

Heating degree day (HDD) is a parameter designed to measure the demand for energy needed to heat a building. HDD is derived from measurements of outside air temperature. The heating requirements for a given building at a specific location are considered to be directly proportional to the number of HDD at that location.

HDD are defined relative to a base temperature: the outside temperature above which a building needs no heating. The most appropriate base temperature for any particular building depends on the temperature, which the building is heated to, and the nature of the building, including the occupants and the heat-generating equipment within it. In Italy, the base temperature is an indoor temperature of $20^{\circ} \mathrm{C}$ which is adequate for human comfort (Presidential Decree 412/93 and subsequent amendments) [1,2].

A similar measurement, cooling degree day (CDD), reflects the amount of energy used to cool a building when the perceived outside temperature is above a certain value that people consider uncomfortable and start using air conditioning to cool their buildings.

There are a number of ways in which HDD and CDD can be calculated. The more detailed a record of temperature data, the more accurate the HDD and CDD can be calculated.

HDD are often calculated using simple approximation methods that use daily temperature readings instead of more detailed temperature records such as half-hourly readings. One popular approximation method is to take the average temperature on any given day, and subtract it from the base temperature. If the value is less than or equal to zero, that day has zero HDD. But if the value is positive, that number represents the number of HDD on that day.

Unlike the winter, in the summer season the energy demand for cooling is a function of not one but a series of meteorological parameters. The perceived temperature depends on both the air temperature and relative humidity. To properly define the cooling degrees day (CDD) there is a need of using Humidex, that is a short for humidity index. This index is used by Canadian meteorologists to describe how hot the weather feels to the average person by combining the effect 
of temperature and humidity [3].

Humidex is a dimensionless quantity based also on the dew point. CDD is the difference between the perceived average daily temperature through the Humidex (Hmed) value and the base value that in Italy is set equal to 25 (name UNI 10339 and 10349) [4]. This roughly means that when the perceived temperature is above $25^{\circ} \mathrm{C}$, air conditioning is required to cool a building and the relative CDD value provides a scale to determine the needed energy consumption.

An entire urban area can be characterized by different micro-climates. This is particularly true for Naples, a one million people city facing the Tyrrhenian Sea in Central Italy. This city has a complex morphology made of hills and depressions, spanning in altitude from 0 to $400 \mathrm{~m}$ asl. In addition, a significant urban heat island effect is felt inside the city. Thus, it is misleading to characterize a city with a complex morphology using just single mean HDD or CDD values. For example, ENEA reports the HDD of all Italian Cities and Naples has 1034 HDD and it is supposed to be at 17 $\mathrm{m}$ asl [5].

In the following, we evaluate HDD and CDD indexes from measurements of outside air temperature and relative humidity taken from several weather stations optimally distributed inside the city of Naples. We demonstrate and quantify that the demand for energy and the weather comfort significantly depends on the particular city area (e.g.: Posillipo, Centro Storico, Bagnoli, Camaldoli).

This research provides a first zonation of the urban area of Naples regarding the HDD and CDD indexes that can be used by policymakers for an efficient energy demand and supply management.

\section{DATA AND ANALYSIS}

Temperature and relative humidity data with a temporal resolution of 10 minutes were collected from seven meteorological stations distributed in strategic points of the urban area of Naples for the year 2016. One additional meteorological station located in S. Elmo provided data with a daily resolution.

Figure 1 shows their locations while Table 1 collects their geographical coordinates with their respective elevation above the mean sea level. Some locations such as San Marcellino and Via Foria refer to the historical highly populated center of Naples. However, San Marcellino is closer to the sea than Via Foria by about $1 \mathrm{~km}$ so that the latter location feels more the urban heat island effect. Camaldoli, Capodimonte, S. Elmo and Denza on Posillipo hill represent greener areas located at various elevations from 135 to $384 \mathrm{~m}$ asl. Bagnoli and Bacoli are located directly on the coast. Bacoli is countryside town sufficiently far from the main urban area of Naples to be considered nearly free of any urban heat island effect [6].

Table 1. Geographical coordinates of the eight meteorological stations depicted in figure 1

\begin{tabular}{|c|c|c|c|}
\hline & Elevation $(\mathrm{m})$ & Lat. & Long. \\
\hline Bacoli & 3 & 40.792109 & 14.077658 \\
\hline Bagnoli & 30 & 40.814101 & 14.164879 \\
\hline Via Foria & 34 & 40.857821 & 14.258345 \\
\hline San Marcellino Obs. & 50 & 40.847251 & 14.257854 \\
\hline Denza & 135 & 40.801462 & 14.186013 \\
\hline Capodimonte Obs. & 150 & 40.862497 & 14.255778 \\
\hline S. Elmo & 256 & 40.845367 & 14.237617 \\
\hline Camaldoli & 384 & 40.871944 & 14.183136 \\
\hline
\end{tabular}

The original meteorological records were not complete due to various technical problems such as momentarily interruptions. We adjusted the records using linear interpolation for holes shorter than 3 hours. For larger interruptions, first we noted that the various meteorological records are highly cross correlated by evaluating their pairwise correlation coefficients: see Table 2 . Then we used multiregression models based on at least three independent temperature and humidity constructors to construct the missing measurements of each record. We first fixed the already most completed records such as San Marcellino, Capodimonte, Bacoli and Bagnoli using three constructors taken from them. Then we reconstructed the missing records of Denza, via Foria and Camaldoli using previous fixed constructors.

Figures 2 and 3 show the eight temperature and humidity records used in this study.

\begin{tabular}{|c|c|c|c|c|c|c|c|}
\hline Temperature & Bacoli & Bagnoli & Camaldoli & Capodimonte Obs. & Denza & San Marcellino Obs. & Via Foria \\
\hline Bacoli & 1.00 & 0.99 & 0.96 & 0.98 & 0.98 & 0.98 & 0.97 \\
\hline Bagnoli & 0.99 & 1.00 & 0.95 & 0.99 & 0.98 & 0.99 & 0.99 \\
\hline Camaldoli & 0.96 & 0.95 & 1.00 & 0.98 & 0.98 & 0.97 & 0.95 \\
\hline Capodimonte Obs. & 0.98 & 0.99 & 0.98 & 1.00 & 0.98 & 0.99 & 0.98 \\
\hline Denza & 0.98 & 0.98 & 0.98 & 0.98 & 1.00 & 0.98 & 0.94 \\
\hline San Marcellino Obs. & 0.98 & 0.99 & 0.97 & 0.99 & 0.98 & 1.00 & 0.99 \\
\hline Via Foria & 0.97 & 0.99 & 0.95 & 0.98 & 0.94 & 0.99 & 1.00 \\
\hline Relative Humidity & Bacoli & Bagnoli & Camaldoli & Capodimonte Obs. & Denza & San Marcellino Obs. & Via Foria \\
\hline Bacoli & 1.00 & 0.93 & 0.84 & 0.78 & 0.85 & 0.84 & 0.82 \\
\hline Bagnoli & 0.93 & 1.00 & 0.94 & 0.88 & 0.94 & 0.92 & 0.90 \\
\hline Camaldoli & 0.84 & 0.94 & 1.00 & 0.95 & 0.95 & 0.93 & 0.89 \\
\hline Capodimonte Obs & 0.78 & 0.88 & 0.95 & 1.00 & 0.91 & 0.96 & 0.95 \\
\hline Denza & 0.85 & 0.94 & 0.95 & 0.91 & 1.00 & 0.91 & 0.87 \\
\hline San Marcellino Obs. & 0.84 & 0.92 & 0.93 & 0.96 & 0.91 & 1.00 & 0.96 \\
\hline Via Foria & 0.82 & 0.90 & 0.89 & 0.95 & 0.87 & 0.96 & 1.00 \\
\hline
\end{tabular}

Table 2. Pairwise correlation coefficients among the temperature and humidity records using the seven meteorological stations with a 10 -minute time resolution 


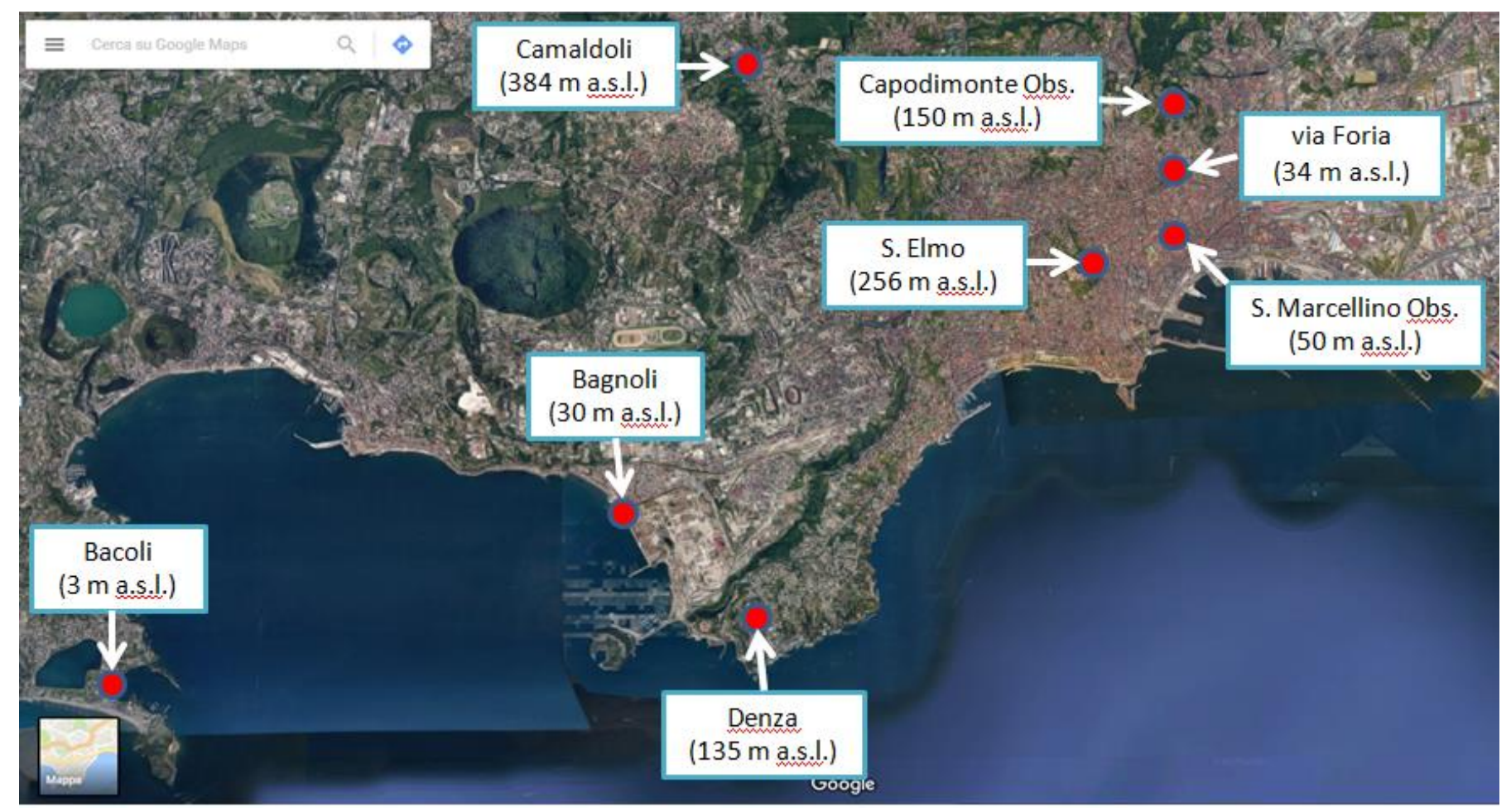

Figure 1. Urban area of Naples and the locations of the eight meteorological stations

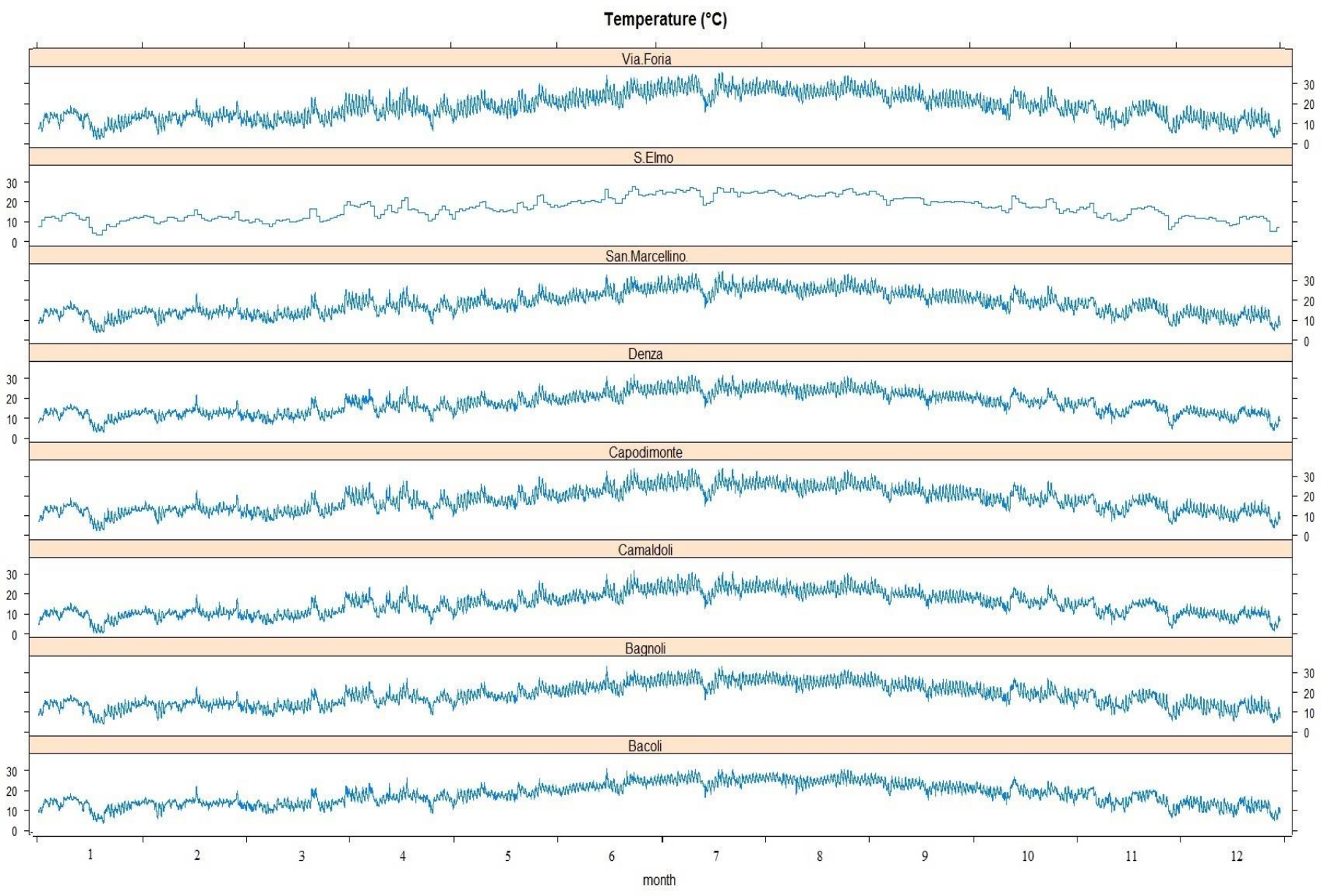

Figure 2. Hourly temperature records for the year 2016 from the eight stations shown in Figure 1. Note that for Sant'Elmo only daily mean values are available 
Relative Humidity (\%)

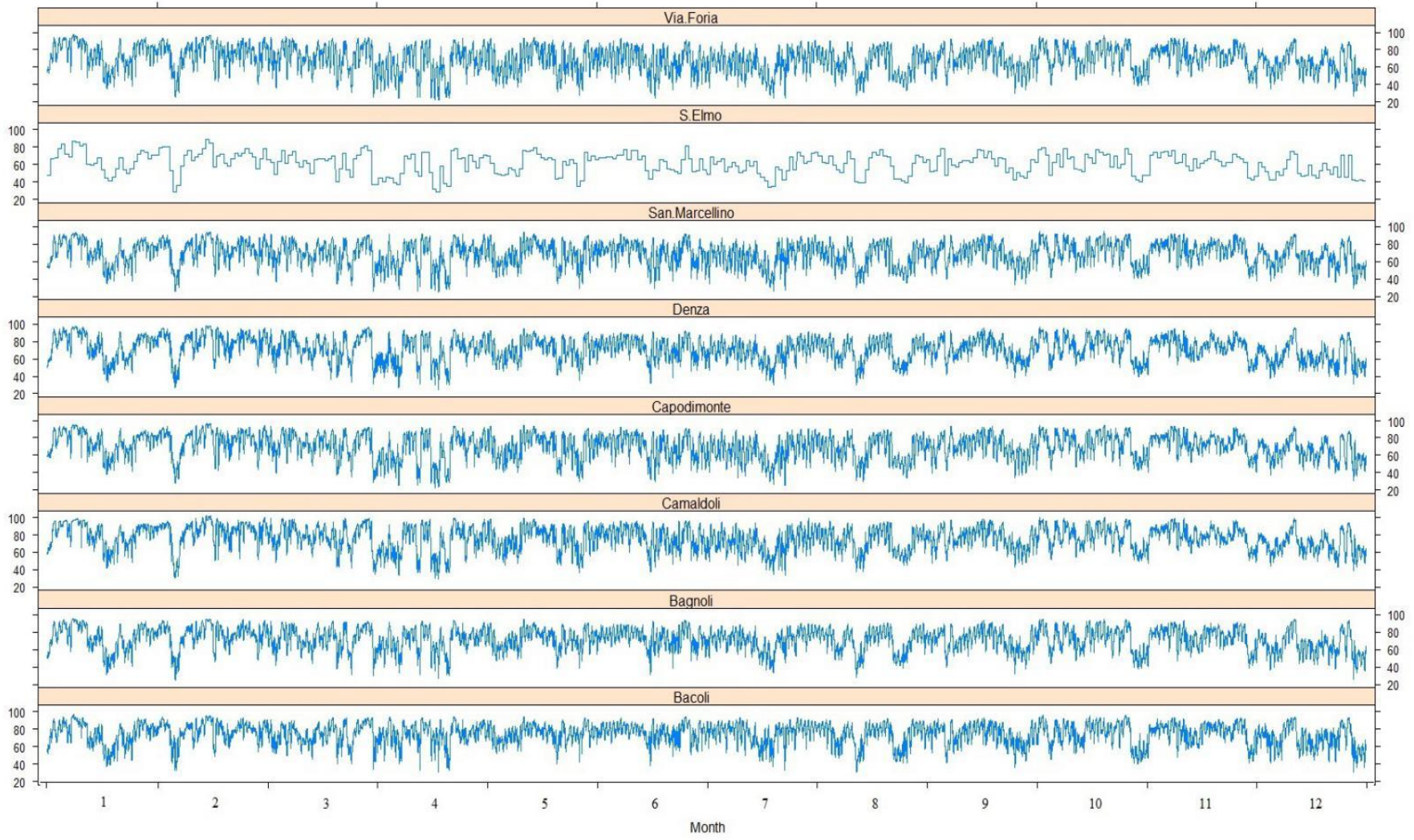

Figure 3. Relative humidity records for the year 2016 from the eight stations shown in Figure 1. Note that for Sant'Elmo only daily mean values are available

\section{Humidex}

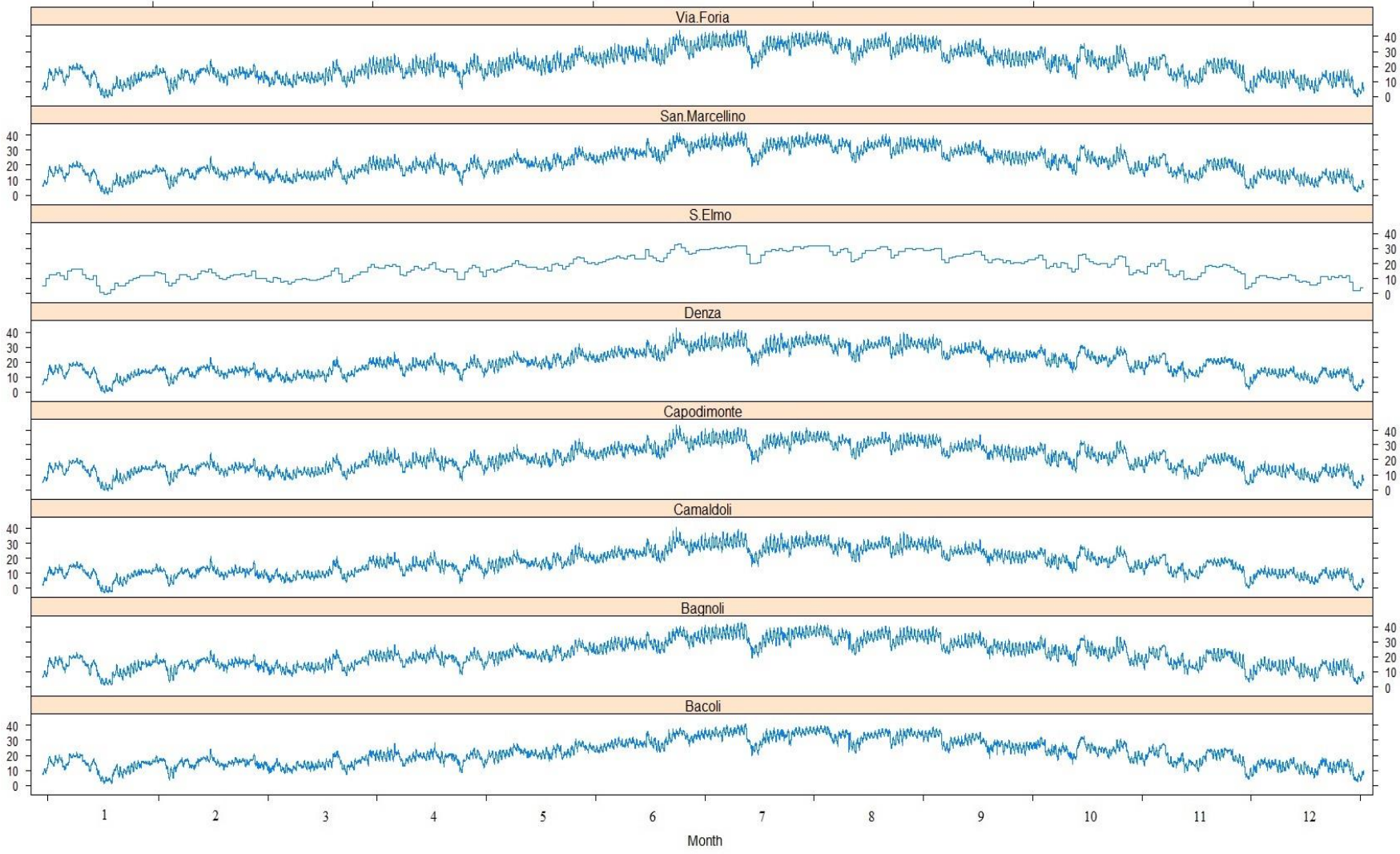

Figure 4. Humidex indexes for the eight locations calculated using the temperature and relative humidity records depicted in Figures 2 and 3, respectively using Eqs. 1, 2 and 3. Note that for Sant'Elmo only daily mean values are available 
Humidex indexes for the eight locations were calculated using the temperature and humidity records depicted in Figures 2 and 3 in the following way.

First, we calculated at each time the dew point temperatures, $\mathrm{T}_{\mathrm{dp}}$, in Kelvin using the Magnus formula [7]:

$$
\begin{aligned}
& \gamma(T, R H)=\ln \left(\frac{R H}{100}\right)+\frac{b T}{c+T}, \\
& T_{d p}=\frac{c \gamma(T, R H)}{b-\gamma(T, R H)}+273.16
\end{aligned}
$$

where $\mathrm{T}$ is the temperature in Celsius degree (shown in Figure 2), $\mathrm{RH}$ is the relative humidity (shown in Figure 3), b=17.62 and $\mathrm{c}=243.12^{\circ} \mathrm{C}$. Then, we calculated the relative Humidex index using the formula [3]:

$$
\text { Humidex }=T_{\text {air }}+0.5555\left[6.11 e^{5417.753\left(\frac{1}{273.16}-\frac{1}{T_{d p}}\right)}-10\right]
$$

The calculated Humidex indexes for the eight locations are depicted in Figure 4.

Table 3 collects the mean, maximum and minimum temperature, the maximum Humidex, and mean summer Humidex for the eight locations depicted in Figure 1. It also reports the mean daily temperature and humidex excursions and the Ivanov continental index [10]: the climate is maritime for $I=69-82$; weakly maritime, $I=83-100$; weakly continental, $\mathrm{I}=101-121$.
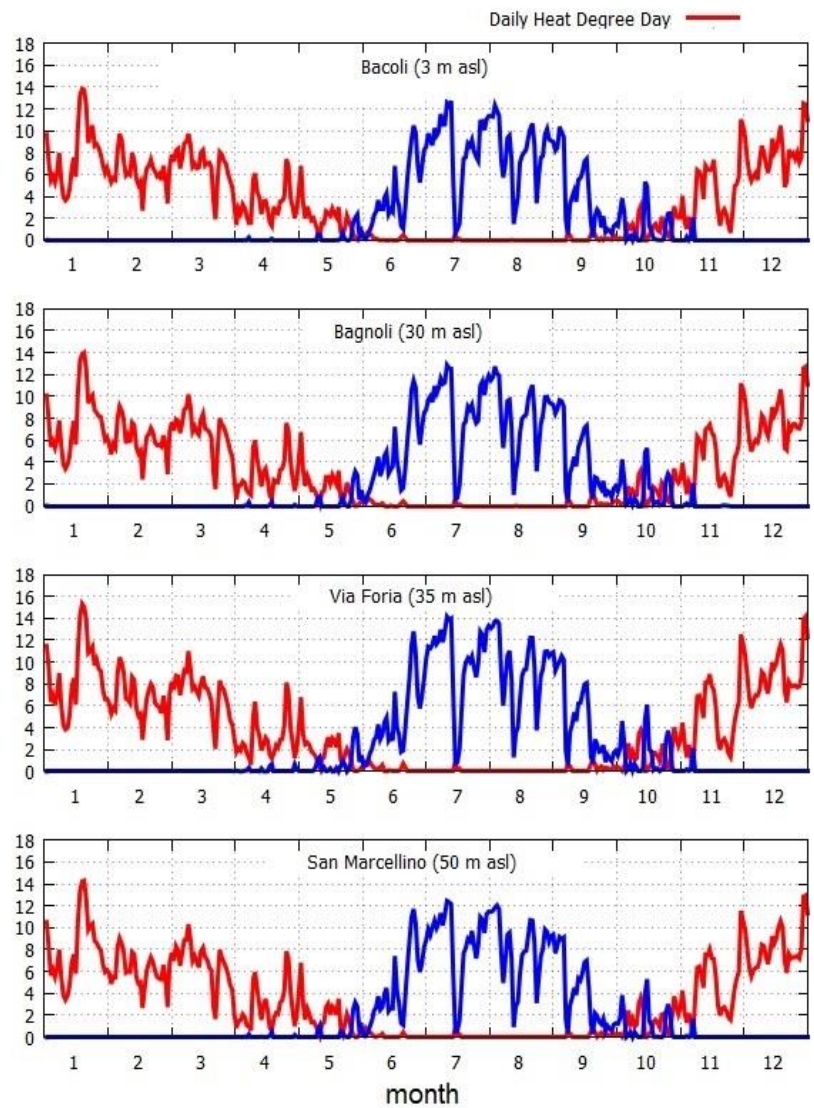

Finally, we use the air temperature and the humidex records depicted in Figures 2 and 4 to evaluate the daily HDD and CDD records by adding the 10-minute contributions using $20^{\circ} \mathrm{C}$ and 25 , respectively, as base values for each of the eight locations. We report the curves in Figure 5 and the annual HDD and CDD sums are reported in Figure 6. The bars are depicted in order of elevation from the mean sea level of each meteorological station

\begin{tabular}{|c|c|c|c|c|c|c|c|c|}
\hline & $\begin{array}{c}\text { Temp } \\
\text { mean } \\
\left({ }^{\circ} \mathrm{C}\right)\end{array}$ & $\begin{array}{c}\text { Temp } \\
\text { max } \\
\left({ }^{\circ} \mathrm{C}\right)\end{array}$ & $\begin{array}{c}\text { Temp } \\
\text { min } \\
\left({ }^{\circ} \mathrm{C}\right)\end{array}$ & $\begin{array}{c}\text { Daily } \\
\text { exc } \\
\left({ }^{\circ} \mathrm{C}\right)\end{array}$ & $\begin{array}{c}\text { Hmdx } \\
\text { max }\end{array}$ & $\begin{array}{c}\text { Sum } \\
\text { Hmdx } \\
\text { mean }\end{array}$ & $\begin{array}{c}\text { Daily } \\
\text { Hmdx } \\
\text { exc }\end{array}$ & $\begin{array}{c}\text { Ivanov } \\
\text { index } \\
\text { I }\end{array}$ \\
\hline Bacoli & 18.3 & 31.2 & 3.7 & 3.3 & 40.7 & 32.5 & 3.8 & 79 \\
\hline Bagnoli & 18.5 & 33.0 & 4.0 & 4.3 & 42.8 & 32.7 & 5.2 & 88 \\
\hline Via Foria & 18.5 & 35.9 & 2.3 & 5.6 & 44.2 & 33.6 & 6.3 & 103 \\
\hline $\begin{array}{c}\text { San } \\
\text { Marcellino } \\
\text { Obs. }\end{array}$ & 18.5 & 34.7 & 3.6 & 4.3 & 42.9 & 32.5 & 4.8 & 92 \\
\hline Denza & 17.5 & 32.0 & 3.0 & 3.4 & 42.9 & 30.6 & 4.0 & 85 \\
\hline $\begin{array}{c}\text { Capodimonte } \\
\text { Obs. }\end{array}$ & 17.9 & 34.4 & 2.4 & 4.4 & 43.9 & 31.6 & 4.9 & 93 \\
\hline S. Elmo $(*)$ & 16.8 & 27.5 & 3.5 & & 33.2 & 28.1 & & \\
\hline Camaldoli & 15.3 & 31.6 & 0.5 & 3.7 & 40.8 & 27.8 & 4.4 & 84 \\
\hline
\end{tabular}

Table 3. Mean, maximum and minimum temperature, maximum Humidex, and mean summer Humidex value for the seven locations depicted in Figure 1 using the 10-minutes resolution. (*) S. Elmo uses the daily record. The annual average daily thermal and humidex excursion between day and night are added. The last column reports the Ivanov continental index I. The sites are listed in elevation order
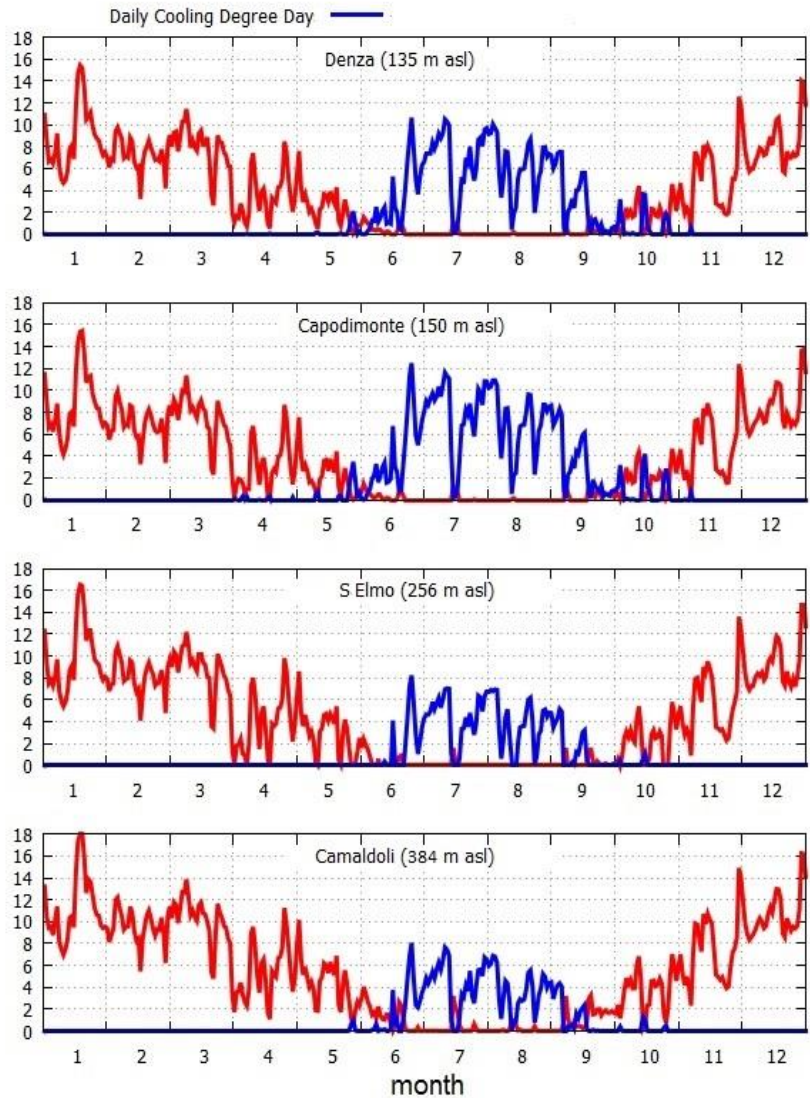

Figure 5. [A] daily heat (red) and cool (blue) degree days for the eight locations 


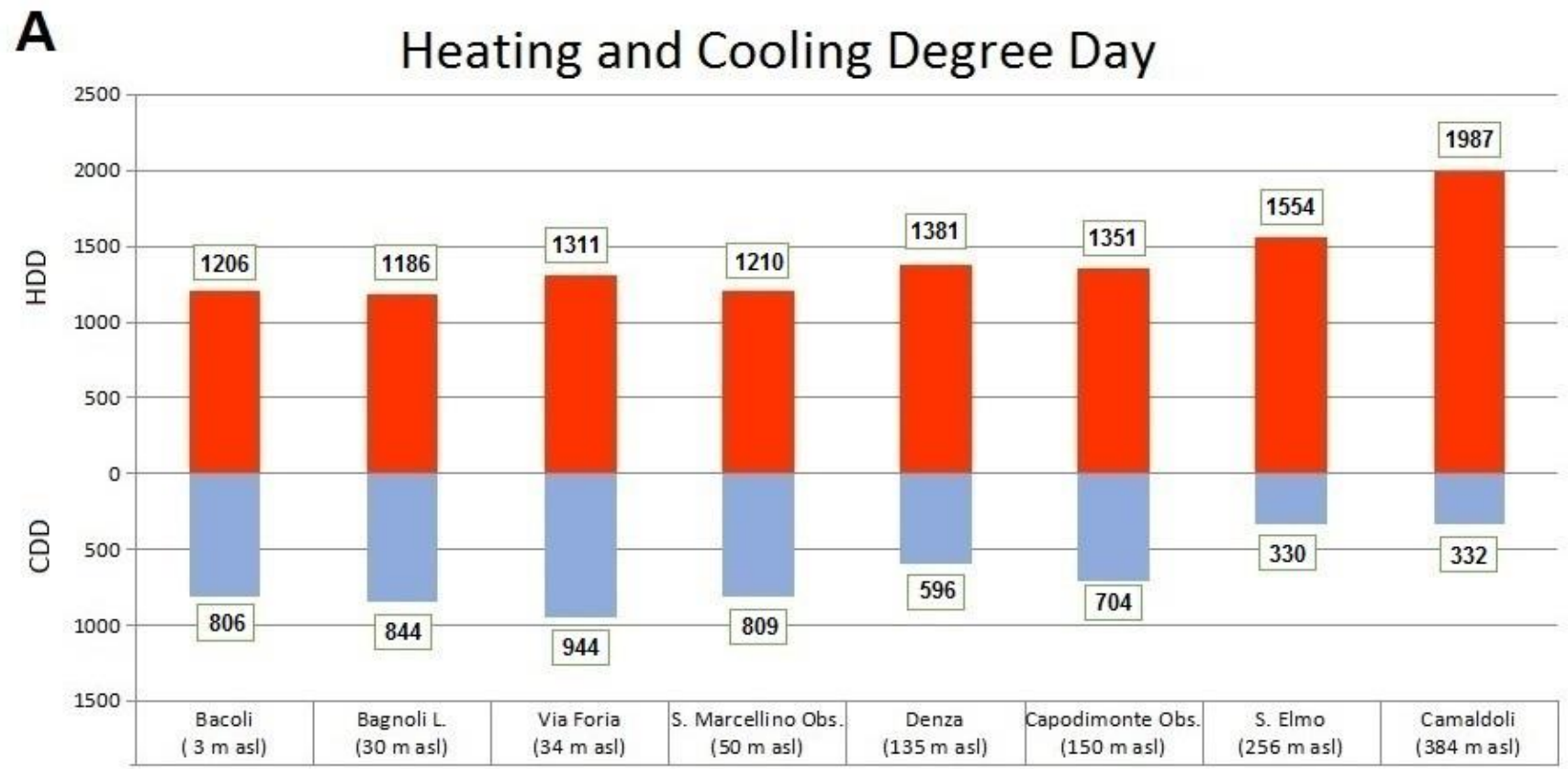

B

\section{Heating + Cooling Degree Day}

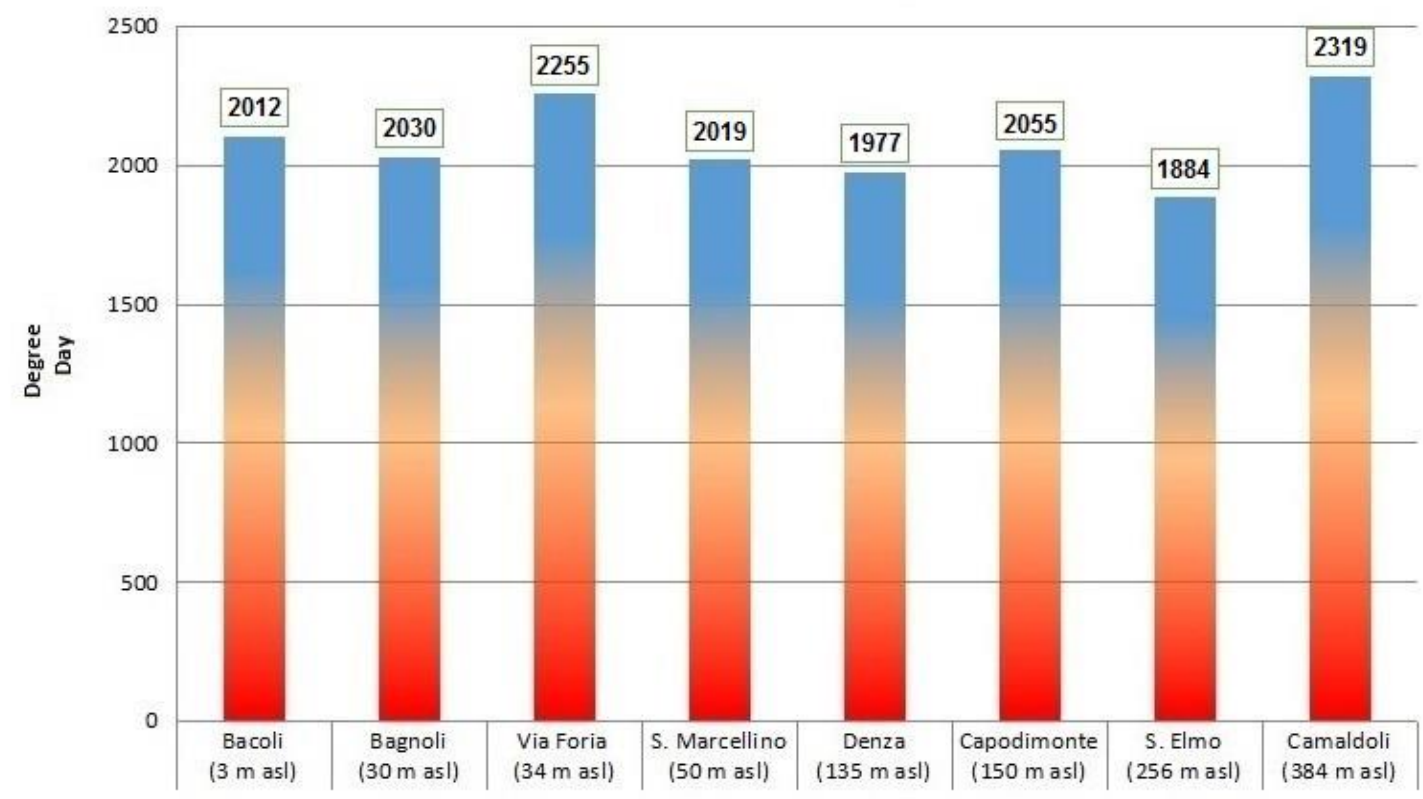

Figure 6. [A] Annual heat and cool degree days. [B] combined heat and cool degree days. The sites are listed in elevation order

\section{DISCUSSION AND CONCLUSIONS}

Herein we have collected high resolution temperature and relative humidity data from eight locations of the urban area of Naples for the year 2016. These locations are characterized by different environments (from less to denser populated, close or far from the coast and at various elevations from the mean sea level from 3 to $384 \mathrm{~m}$ ), as Figure 1 shows. Thus, the expectation is that these zones could be characterized by different micro-climates that also yields to different energy demands and supplies to heat or cool their buildings.

We have used meteorological temperature and relative humidity records to estimate the correspondent humidex index and, then, use the temperature and the humidex records to calculate the HDD and CDD indexes, respectively, using $20^{\circ} \mathrm{C}$ and 25 as base values, respectively.

By comparing the results listed in Table 1 and the locations in Figure 1, it appears that the annual mean temperature tends to decrease with the elevation with Bacoli $(3 \mathrm{~m}$ asl $)$ about $3^{\circ} \mathrm{C}$ warmer than Camaldoli (384 $\mathrm{m}$ asl): thus, the average lapse rate is about $0.78^{\circ} \mathrm{C}$ per $100 \mathrm{~m}$. However, the historical center of Naples (San Marcellino and via Foria) is characterized by the highest maximum temperatures. Capodimonte ( $150 \mathrm{~m}$ asl) is also warmer than Denza (135 m asl) on Posillipo hill despite located at a higher elevation because far from the coast.

By looking at the Humidex index, 10-minutes maximum values between 40 and 45 are recorded in all locations. S. Elmo data are daily means and it is not possible from them to deduce the 10-minutes maximum. This humidex interval is considered alarming because associated to intense discomfort [8]. In fact, 
several deaths occur in Naples in correspondence of large heat waves [9]. S. Elmo is characterized by an annual temperature variation from a mean daily minimum of $3.5^{\circ} \mathrm{C}$ to a mean daily maximum of $27.5^{\circ} \mathrm{C}$. From alternative data we could estimate for S. Elmo a 2016 annual minimum at the 10minutes scales of $1.6^{\circ} \mathrm{C}$ and an annual maximum of $32.2^{\circ} \mathrm{C}$. Camaldoli is characterized by a significantly larger temperature variation (from $0.5^{\circ} \mathrm{C}$ to $31.6^{\circ} \mathrm{C}$ ) and a significant higher maximum humidex (40.8) despite its location is $128 \mathrm{~m}$ higher because it is far from the coast. Denza (close to the coast and at $135 \mathrm{~m}$ asl) is characterized by a moderate and pleasant climate. Via Foria, in the innerness of Naples and far from the coast, is characterized by very warm summers (maximum $35.9^{\circ} \mathrm{C}$ ), cool winters (minimum $2.3^{\circ} \mathrm{C}$ ) and the worst humidex of the city (maximum 44.2).
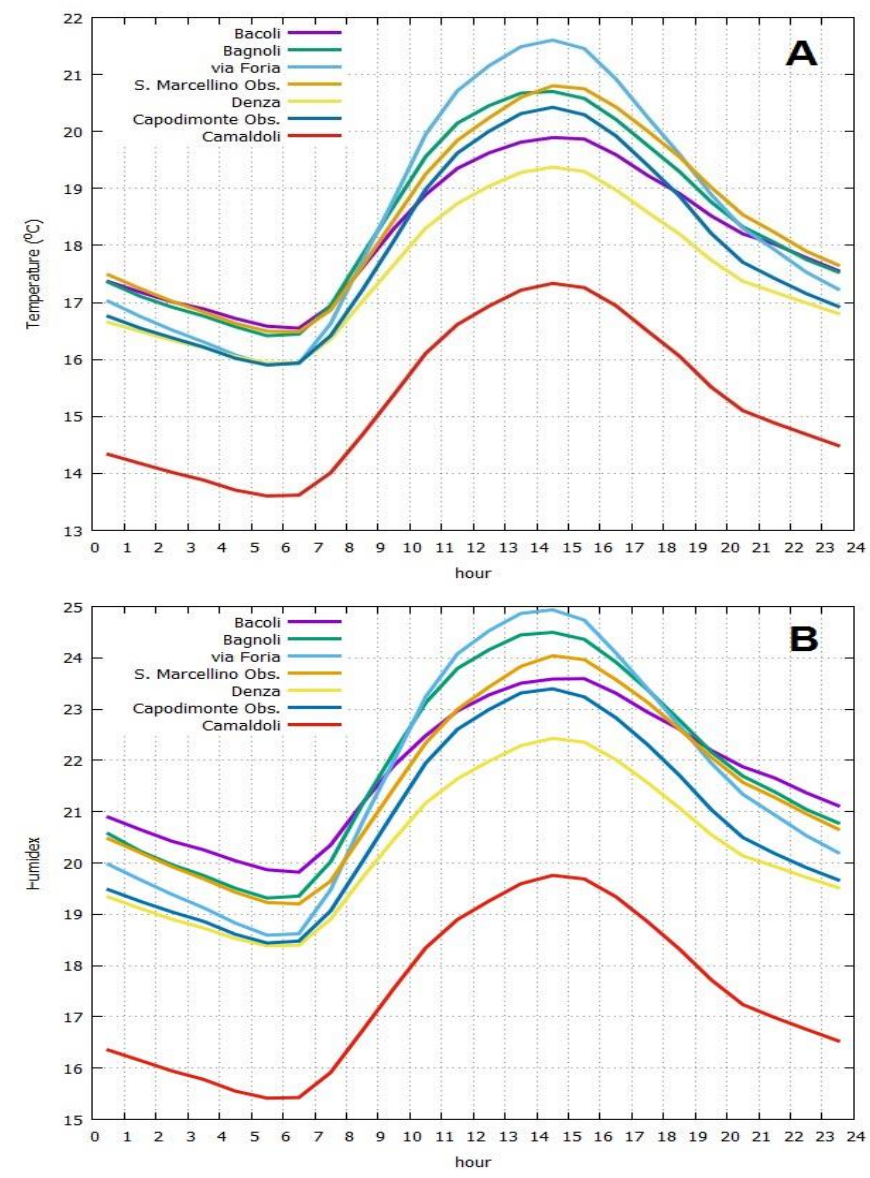

Figure 7. Annual mean daily temperature oscillation

The analysis of the HDD and CDD indexes tend to increase or decrease, respectively, with the elevation, as would be expected. The annual HDD is minimum in Bagnoli (1186) located near the coast in a relatively densely populated area, and it is maximum in Camaldoli (1987) with is located in the interior at $384 \mathrm{~m}$ asl. The annual CDD is maximum in via Foria (944) and minimum in the mild S. Elmo (330).

By combining HDD and CDD in a unique index (Figure 6B), the energy demand and supply to heat or cool buildings in Naples corresponds to about 2080 with a minimum in S. Elmo (1884) and a maximum in Camaldoli (2319). Particularly interesting is the high total energy demands in via Foria (2255), and the low energy demands in Denza on Posillipo hill (1977). Because Camaldoli is scarcely populated, S. Elmo meteorological station is located inside a green park and Bacoli is outside Naples on the coast, the typical mean annual energy demands in populated areas of Naples is comprised between 1977-2030 in most zones. However, in the densely populated zone of via Foria the energy demands are about $10 \%$ more than in the other main locations of Naples.

The anomalous behavior observed in via Foria is also explained by Figure 7 that depicts the annual mean temperature and humidex daily oscillation of the temperature observed in the seven locations where the 10-minute resolved meteo records are available: see also Table 2. In Via Foria, the daily oscillation is the largest one among the various available records. The explanation is that via Foria is located far from the coast, in a depression and in a fully urbanized zone. This location is weakly continental according to its Ivanov index [10] $(\mathrm{I}=103)$ in respect to the other locations, which are maritime or weakly maritime: see Table 3 . This makes via Foria more sensitive to the daily and seasonal oscillations: it gets relatively warm in summer and during day times and relatively cool in winter and night times.

The methodology adopted in this paper can be applied to other locations and/or improved with additional meteorological stations. Further research is expected to fully improve the HCC and CDD zonation of Naples, because cities and climate [11] are also evolving, HCC and CDD in a specific location can also evolve in time.

\section{REFERENCES}

[1] Ente Italiano di Normazione. (2008). UNI EN ISO 15927-6: 2008, from http://store.uni.com/magento1.4.0.1/index.php/uni-en-iso-15927-6-2008.html, accessed on 31/8/2017.

[2] DECRETO DEL PRESIDENTE DELLA REPUBBLICA 26 agosto 1993, n. 412. from http://www.normattiva.it/urires/N2Ls? urn:nir:stato:legge:1993-08-26;412, accessed on 31/8/2017.

[3] Government of Canada. (2016). Spring and Summer Hazards. Environment and Climate Changes.

[4] Riscaldamento e raffreddamento degli edifici: dati climatici, UNI 10349:1994/EC. from https://www.scribd.com/doc/210137104/UNI-10349Dati-Climatici, accessed on 31/8/2017.

[5] ENEA. Tabella dei gradi/giorno dei Comuni italiani raggruppati per Regione e Provincia. from http://efficienzaenergetica.acs.enea.it/doc/dpr41293 allA tabellagradigiorno.pdf, accessed on 31/8/2017.

[6] Fortelli A., Scafetta N., Mazzarella A. (2016). Local warming in historical center of Naples: urban heat island through thermic city analysis, International Journal of Heat and Technology, Vol. 34, No. Sp. 2, pp. S569-S572. DOI: 10.18280/ijht.34S252

[7] Sonntag D. (1990). Important new values of the physical constants of 1986, vapour pressure formulations based on the ist-90 and psychrometer formulae, Z. Meteorol., Vol. 70, No. 5, pp. 340-344.

[8] Canadian Humidex Calculator. from http://www.csgnetwork.com/canhumidexcalc.html, accessed on 31/8/2017.

[9] Di Cristo R., Mazzarella A., Viola R. (2007). An analysis of heat index over Naples (Southern Italy) in the context of European heat wave of 2003, Natural 
Hazards, Vol. 40, pp. 273-379. DOI: 10.107/s11069006-003-7

[10] Ivanov N. (1959). Belts of continentality on the globe, Izv. Vses. Geogr. Obshch, Vol. 91, pp. 410-423.

[11] Scafetta N. (2016). Problems in modeling and forecasting climate change: CMIP5 general circulation models versus a semi-empirical model based on natural oscillations, International Journal of Heat and Technology, Vol. 34, No. Sp. 2, pp. S435-S442. DOI: 10.18280/ijht.34S2 